\title{
THE REQUIREMENTS FOR EFFICIENT OVERVOLTAGE PROTECTION OF ELECTRONIC DEVICES IN LOW-VOLTAGE POWER SYSTEMS
}

\author{
Vladan Radulović, Zoran Miljanić
}

Original scientific paper

The increasing sensitivity of electronic devices widely used in low-voltage AC systems requires an appropriate protection against voltage and current surges. Protection of the equipment against the prospective surges is based on application of surge protection devices (SPDs). Most common situation, especially in residential buildings, is application of only one SPD at distribution board. In the paper, comprehensive analysis of this type of overvoltage protection system with wide ranges of influencing parameters is performed through experimental measurements and number of simulations. Obtained results show that existence of built-in varistors within electronic devices, with low protection voltages causes their thermal destruction due to inadequate distribution of surge energy between SPD and varistors. The requirements for efficient protection system which will provide survival of built-in varistors, as well as proper overvoltage protection characteristics are described and discussed in the paper.

Keywords: low-voltage power systems; overvoltage protection; surge protection devices

Zahtjevi za efikasnu prenaponsku zaštitu elektronskih uređaja u niskonaponskim instalacijama

Izvorni znanstveni članak

Povećana osjetljivost elektroničkih uređaja naširoko korištenih u niskonaponskim instalacijama zahtijeva odgovarajuću prenaponsku zaštitu. Zaštita opreme od potencijalnih prenapona se temelji na primjeni uređaja za zaštitu od prenapona (UZP). Najčešća situacija, posebno u stambenim zgradama, je primjena samo jednog UZP instaliranog u razdjelnom ormaru. Sveobuhvatna analiza ovakvog sustava prenaponske zaštite u širokim rasponima ovisnih parametara je provedena eksperimentalnim mjerenjima i velikim brojem simulacija. Dobiveni rezultati pokazuju da postojanje ugrađenih varistora unutar elektroničke opreme, s niskim zaštitnim naponima uzrokuje njihovo termičko uništenje zbog neadekvatne raspodjele energije prenapona između UZP i varistora. U radu su razmotreni zahtjevi za efikasnim sustavom zaštite koji neće izazvati uništenje ugrađenih varistora, i koji će pružiti odgovarajuće karakteristike prenaponske zaštite.

Ključne riječi: niskonaponske instalacije; prenaponska zaštita; uređaji za zaštitu od prenapona

\section{Introduction}

Advanced electric and electronic equipment widely used nowadays both in residential as well as in industrial low-voltage power systems has weak surge withstand capability [1, 2]. The more highly integrated the electronic systems are, the less resistant to voltage and/or current surges they are.

Surge voltages and surge currents occurring in lowvoltage AC power systems are originated from two major sources, lightning and switching. A third phenomenon that has to be taken into consideration is the occurrence of surge voltages resulting from interactions between different systems, such as the power system and a communications system, caused by surge events occurring in one of the systems [3]. These surges may be of magnitudes that are dangerous for control units and instruments and, besides damage, can cause upset, resetting of microchip's systems, disturbances or malfunctioning of both analogue and digital solid state components $[2,4]$. It is very difficult to predict the transient response of the low-voltage power networks, because they are often very complex [5]. Typically, they have a great diversity of connected loads, the number and location of the conductors, and the number of branches and routings [5]. Also, port impedance characteristics of household appliances are complex, and for some appliances, the impedance characteristics are different in operating state and non-operating state [6]. Electronic devices, themselves or as part of control and/or monitoring elements, are usually equipped with switch power supply units. This equipment can be modelled as capacitor-charging circuits in the analysis of surges, particularly for the discussion of load effect [7].

Protection of electronic equipment from upset and damage caused by surges in low-voltage AC power systems is an important problem in electromagnetic compatibility. Most of modern devices, especially electronic equipment have already installed built-in varistors to suppress the transient overvoltage at their terminals $[6,8]$. In the race for lower protection and clamping voltages, equipment manufacturers install varistors with very low protection voltages, which subsequently cause their low energy absorption capability. Therefore, this kind of built-in varistors may be thermally damaged when high voltage surges emerge [9].

In order to avoid negative effects of surges to the equipment, surge and overvoltage protection is required. This protection relies on application of surge protective devices (SPDs). It is mostly based on metal oxide varistors (MOV), but other types such as: gas discharge tubes, avalanche diodes, triggered-spark technologies, memristor-spark-gap [10] etc. can be found as well. Their efficiency in providing proper protection depends on the large number of influencing parameters. SPDs characteristics as well as their location in the power installations have to be carefully analysed in order to provide proper equipment protection $[11,12]$.

Application of only one SPD at service entrance or distribution board is widely used overvoltage protection system, especially in residential buildings. Most of the users accept this situation due to confidence in building developers and in device self-protective characteristics declared by manufacturers. 
In order to analyse performances of this type of wide ranges of influencing parameters is performed through experimental measurements and number of simulations. As obtained results will show, low protection voltages of built-in varistors, although emphasized as their advantage by equipment's manufacturers, may cause their thermal overload followed by failure of equipment elements, which were to be protected by varistors. In order to overcome these problems, solutions and requirements for efficient overvoltage protection are given and described in the paper.

\section{Overvoltage protection of sensitive equipment in low- voltage power systems}

Due to increasing miniaturization trends, modern electric and electronic equipment (such as computers, printers, TV sets, control and monitoring units etc.) have low withstand impulse voltage. According to IEC standard 60664-1 [13], these devices belong to overvoltage category I, whose value of withstand impulse voltage is $1500 \mathrm{~V}$. It should be kept in mind that this value corresponds to value of insulation level, and that overvoltages with lower amplitudes can cause upset, malfunctioning or internal problems of these devices. Therefore, in order to prevent such scenarios, varistors installed in the devices have very low protection voltages, usually below $500 \mathrm{~V}$. Furthermore, mentioned devices normally have switching mode power supplies units with filters based on capacitors.

As already mentioned, built-in varistors hardly can provide reliable surge protection, due to their low energy absorption capability and failure under high energy surges. Most likely situation to be found in typical residential buildings is the application of only one SPD on service entrance or on distribution board after energy meter device. According to IEC standard 61643-11 [14], these SPDs are either Type 1 (installed at service entrance) or Type 2 (installed at distribution board), or combination Type 1 and 2 SPD [8]. For the purpose of surge testing and analyses of this type of overvoltage protection, circuit layout given in Fig. 1 is observed.

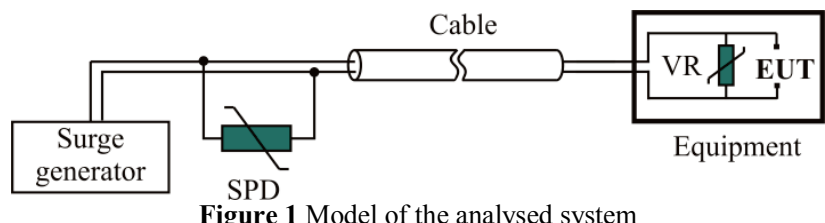

Surge testing of equipment is intended to assess the response of a piece of equipment to the surge environment [15]. Surge testing of SPDs is intended to determine their characteristics (protection level and surgehandling capability) and eventually compare the performance of different designs [16]. The wide variety of surges with different magnitudes, durations and waveforms can be expected to occur in low-voltage AC power systems [3]. There are no specific models that are representative of all surge environments. In order to assure uniform, meaningful and reproducible surge testing of equipment and/or SPDs, it is necessary that this variety overvoltage protection system, comprehensive analysis of surges be modelled with a few representative surges [3].

IEEE standard C62.41.1 [3] as well as IEC standard 61000-4-5 [17] defines Combination Wave as standard representative surge. The Combination Wave involves two waveforms, an open-circuit voltage and a shortcircuit current. Combination Wave is delivered by Combination Wave Generator (CWG) that applies a $1,2 / 50 \mu$ s voltage wave across an open circuit and an $8 / 20$ $\mu \mathrm{s}$ current wave into a short circuit [18]. The exact waveform that is delivered is determined by the generator and the impedance of the equipment under test (EUT) to which the surge is applied [18]. Amplitudes of opencircuit voltage and short-circuit current are determined by location category [16]. In present study, the CWG with open-circuit 1,2/50 $\mu$ s voltage waveform's amplitude of 6 $\mathrm{kV}$ and short-circuit $8 / 20 \mu \mathrm{s}$ current waveform's amplitude of $3 \mathrm{kA}$ is used as surge generator in surge testing circuit given in Fig. 1.

\section{Experimental measurements}

Experimental measurements in the circuit given in Fig. 1 are performed for the purpose of initial analysis, as well as for the purpose of further verification of the simulation model by comparing obtained results.

Commercial CWG which fulfils characteristics and tolerances regarding open-circuit voltage waveform and short-circuit current waveform according to IEEE standard C.62.45 standard [18], as well as to IEC standard 61004-5 [17] is used in experiment. Cable used to connect SPD with equipment under test (EUT) i.e. with varistors (VR) inside EUT is PVC cable $3 \times 2,5 \mathrm{~mm}^{2}$. Length of this cable is $60 \mathrm{~m}$, while length of cable between built-in varistors and EUT is $30 \mathrm{~cm}$. SPD used in experiments has protection voltage of $1250 \mathrm{~V}$. It is SPD of type 2 according to IEC 61643-11 standard [14], designed for mounting on distribution board, with maximal discharge current $I_{\max }(8 / 20 \mu \mathrm{s})$ of $15 \mathrm{kA}$, which corresponds to energy absorption capability of $328 \mathrm{~J}$ [12]. Varistor (VR) has protection voltage of $400 \mathrm{~V}$. It is SPD of type 3 according to IEC 61643-11 standard [14], designed for socket mounting, with value of combination wave open circuit voltage of $U_{\mathrm{OC}}=4 \mathrm{kV}\left(I_{\mathrm{SC}}=2 \mathrm{kA}\right)$, which corresponds to energy absorption capability of $14 \mathrm{~J}$.

In order to provide laboratory testing without damage of real devices, frequently independent laboratory capacitoris used as EUT, due to the fact that electronic devices with switch power supply units can be modelled as capacitor-charging circuits in the analysis of surges, particularly for the discussion of load effect [7]. Also, effect of parallel resistor, by which active power of device's supply unit is modelled, can be neglected due to impact of high frequency voltage spectrum at surge front on capacitor [9]. Capacitance of the used capacitor as EUT is 7,5 $\mu \mathrm{F}$, which corresponds to nominal power of $114 \mathrm{VAr}$ at voltage value of $220 \mathrm{~V}$.

Recorded voltage across SPD is given in Fig. 2, while voltage across EUT is given in Fig. 3. The voltages were measured using resistive voltage attenuator probes in differential connection, which give total attenuation of 
1000 times, and therefore the display calibration of the oscillograms has to be multiplied by 1000 .
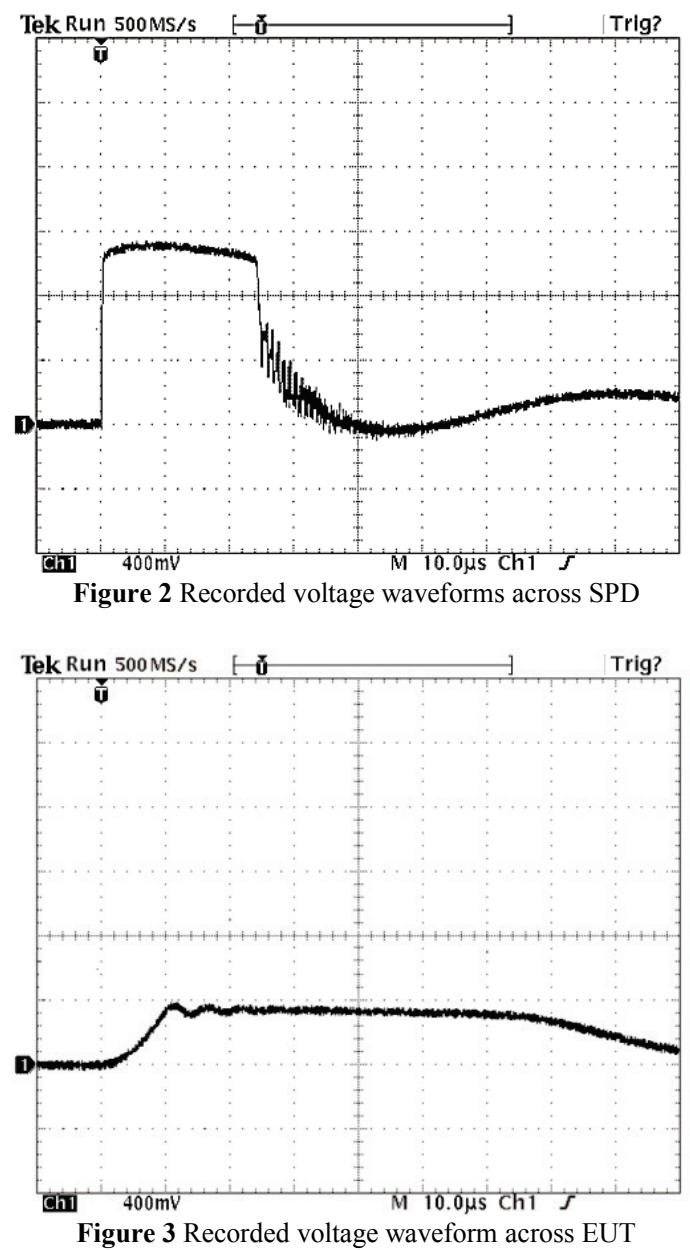

\section{Simulation model}

Simulation model of the observed system in Fig. 1 has been developed in MATLAB Simulink and EMTP/ATP software. The purpose of this simulation model is to provide possibility for analysis with different input parameters and wide ranges of their values.

The model of the CWG is given in Fig. 4. Output of CWG regarding 1,2/50 $\mu$ s open-circuit voltage waveform and $8 / 20 \mu \mathrm{s}$ short-circuit current waveform satisfy tolerances given in international standards [17, 18]. Amplitudes of open-circuit voltage and short-circuit current are $6 \mathrm{kV}$ and $3 \mathrm{kVA}$, respectively. Parameters of CWG electrical circuit are: $U=6,247 \mathrm{kV}, C_{1}=12,5 \mu \mathrm{F}, L_{1}$ $=2,45 \mu \mathrm{H}, L_{2}=4 \mu \mathrm{H}, R_{1}=5,83 \Omega, R_{2}=1,41 \Omega$ [2].

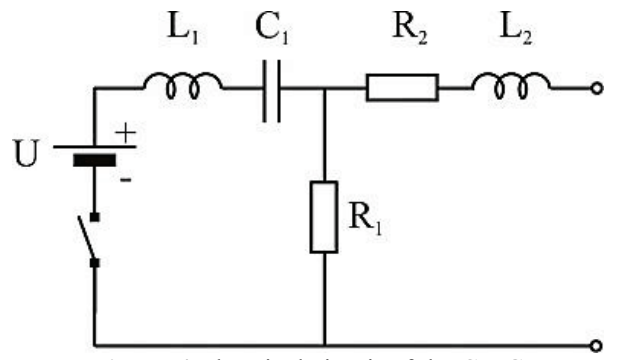

Figure 4 Electrical circuit of the $\mathrm{CWG}$
SPD and VR are modelled as nonlinear elements. Corresponding sets of voltage/current points in the models are obtained from voltage-current curves of SPD and VR, given in manufacturer's data sheets for the same surge protection devices used in experiment.

Parameters of cables are: $R=0,00561 \Omega / \mathrm{m}, L=0,324$ $\mu \mathrm{H} / \mathrm{m}, C=0,1368 \mathrm{nF} / \mathrm{m}, G=0 \mathrm{~S} / \mathrm{m}[2,12]$.

In order to verify validity of simulation model, obtained results from simulations are compared with experimental results for the same case (cable length between SPD and EUT of $60 \mathrm{~m}$ and capacitive power of 114 VAr).

Voltage waveforms across SPD and EUT obtained by simulation model are given in Fig. 5.

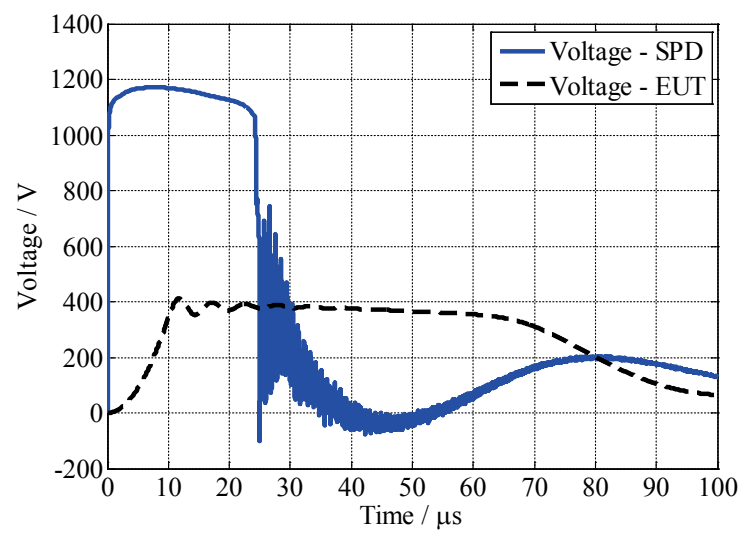

Figure 5 Voltage waveforms across SPD and EUT obtained by using developed simulation model

Results obtained by simulation model (Fig. 5) show good agreement with experimental results (Figs. 2. and 3). Differences between maximal values of observed voltages are less than $5 \%$. This confirms simulation model validity which further can be used for parametric analysis with variations of cable lengths and values of EUT load.

\section{Analysis of the overvoltage performances}

By using developed simulation model, parametric analysis has been performed through number of simulations with wide ranges of influencing parameters.

EUT capacitive load power and length of cable between SPD and VR (cable SPD-VR) in circuit layout given in Fig. 1. are taken as input parameters. EUT capacitive power is varied in range of 1 VAr up to 200 VAr. Length of cable between SPD and VR is varied in range of $1 \mathrm{~m}$ to $100 \mathrm{~m}$. Cable length between VR and EUT is kept constant at the value of $30 \mathrm{~cm}$.

Maximal values of voltages across EUT are given in Fig. 6. It can be observed that maximal values across EUT are lower than withstand insulation level of $1500 \mathrm{~V}$ for overvoltage category I. The reason for this is short cable between VR and EUT. However, maximal values of voltages across EUT are equal or even higher than varistor's protection voltage. This is particularly the case for short cable between SPD and VR and for almost all values of EUT capacitive load power. For the purpose of illustration, voltage waveforms across EUT and VR for case of cable SPD-VR length of $1 \mathrm{~m}$ and EUT load power of $22 \mathrm{VAr}$ are given in Fig. 7. Value of $22 \mathrm{VAr}$ is taken as 
representative case of personal computers' average capacitive power [20].

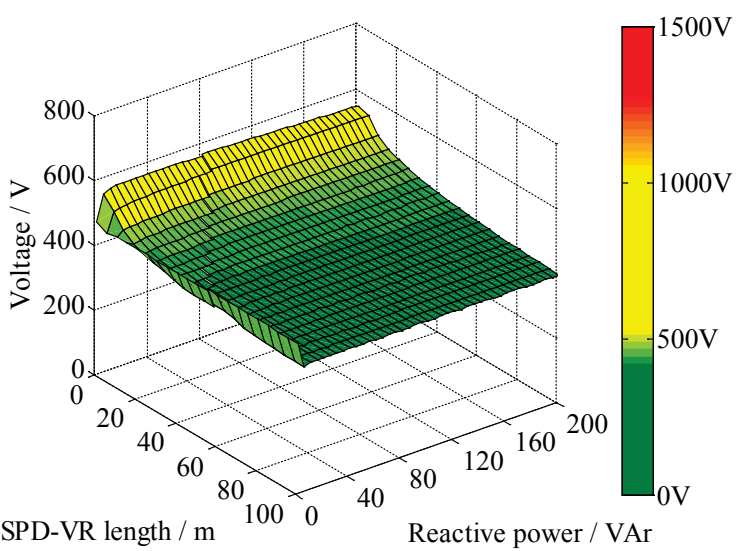

Figure 6 Maximal voltages across EUT

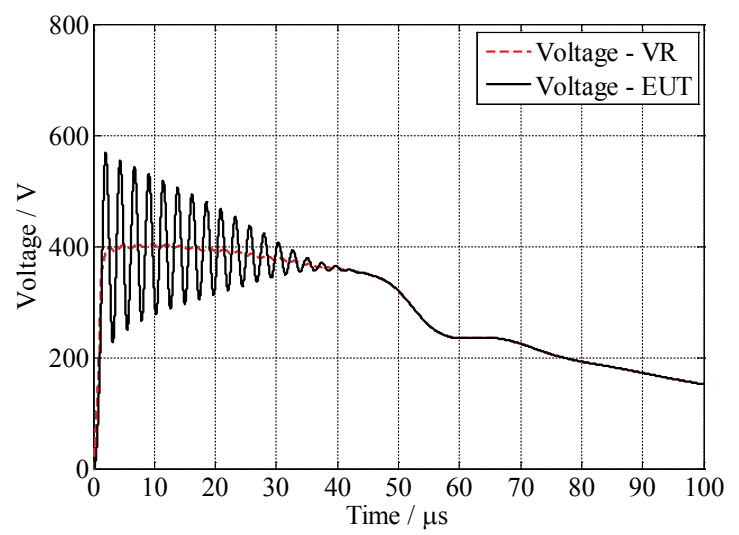

Figure 7 Voltage waveform across EUT and VR for cable SPD-VR length of $1 \mathrm{~m}$ and capacitive power of $22 \mathrm{VAr}$

Values of energies deposited in SPD for different values of cable SPD-VR lengths and EUT load powers are given in Fig. 8.

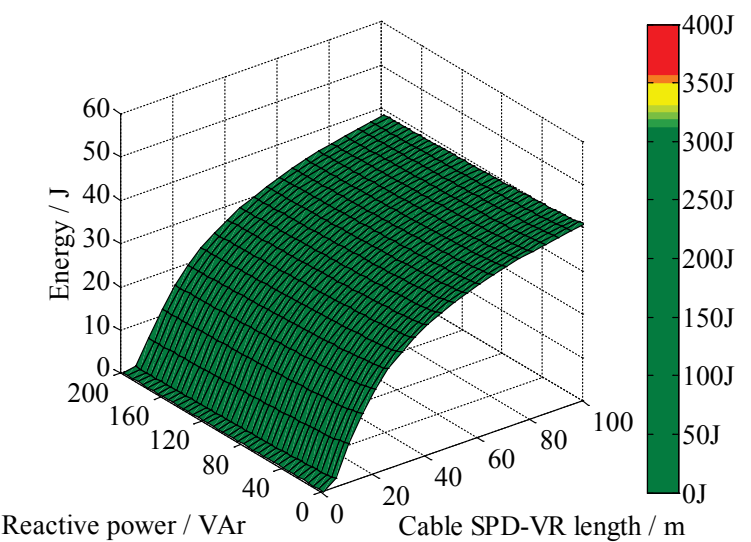

Figure 8 Energy deposited in SPD

Values of energies deposited in VR for different values of cable SPD-VR lengths and EUT load powers are given in Fig. 9.

Energies deposited in SPD are significantly lower than SPD's energy absorption capability (Fig. 8). The reason for that is the fact that SPD is Type 2, according to IEC standard 61643-11 [14], which is characterized by high energy absorption capability. Furthermore, it can be observed that energy deposited in SPD decreases in cases of short cables SPD-VR. The reason for this is voltage drop across cable SPD-VR. For steep surge currents the inductive part of this voltage drop along the cable is dominant. By observing the part of the circuit which consists of SPD, VR and cable between them, it can be noticed that voltage across SPD is equal to sum of voltage across VR and voltage drop on the cable. In case of short cable between SPD and VR, the inductive voltage drop is not sufficient to bring SPD in state of large current conduction. Therefore, higher part of surge current and energy is let-through toward VR (Fig. 9).

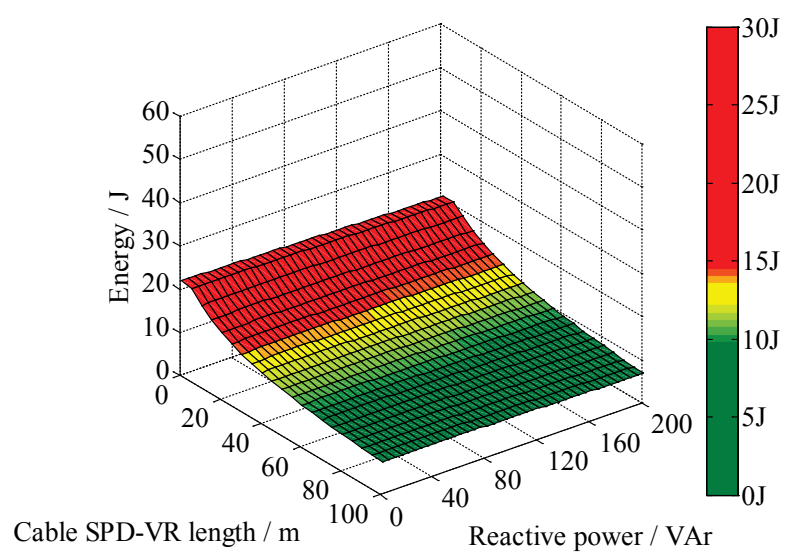

Figure 9 Energy deposited in VR

Furthermore, values of energy deposited in VR are much higher than its energy absorption capability (whose value is $14 \mathrm{~J}$ ) for relatively short cables SPD-VR and almost all values of EUT load power. Fig. 10 shows pattern of combination of dependent parameters (capacitive power and cable SPD-length) with percent values of energy deposited in VR according to its energy absorption capability. Contours with labels are bordering zones in which values exceed certain percent value defined in contour label.

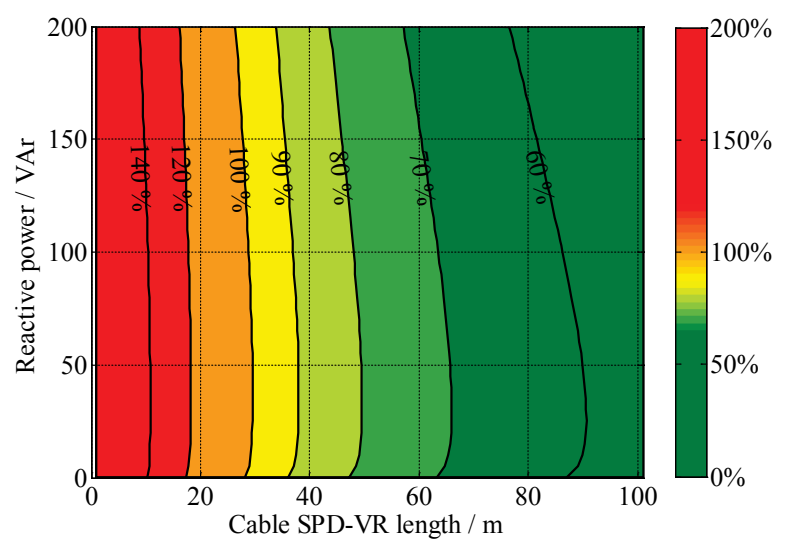

Figure 10 Pattern and zones of percent of energy deposited in VR regarding its energy absorption capability

As it can be observed from Fig. 10, for cable SPDVR lengths less than $30 \mathrm{~m}$ energies deposited in VR exceed its energy absorption capability. As an example, energy distribution between SPD and VR for cable SPDVR length of $10 \mathrm{~m}$ and EUT load power of 22VAr is given in Fig. 11, which shows energy deposited in SPD and VR over time. 


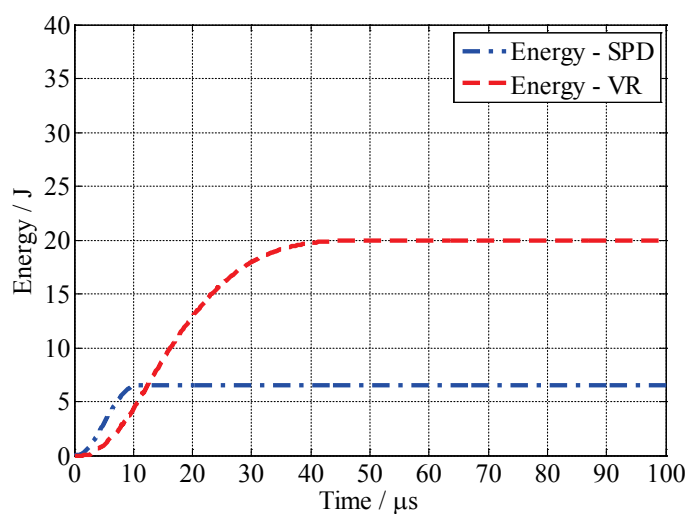

Figure 11 Distribution of energy between SPD and VR for cable SPD -

VR length of $10 \mathrm{~m}$ and EUT load power of $22 \mathrm{VAr}$

Fig. 11 shows that most part of the surge energy would be deposited in VR, while smaller part would be deposited in SPD. But, due to limited energy absorption capability of the VR, this situation leads to its thermal destruction. It can be taken that at the time of approximately $25 \mu \mathrm{s}$, VR will be destroyed. After that, voltage waveform across EUT is given in Fig. 12.

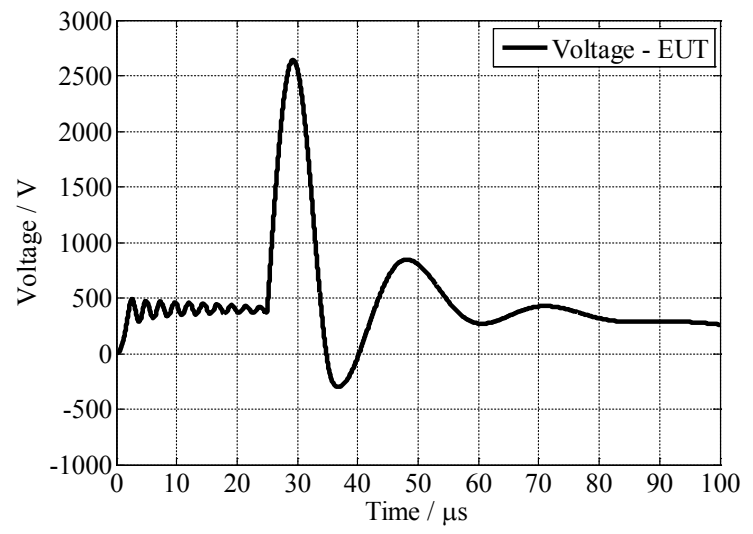

Figure 12 Voltage waveform across EUT after thermal destruction of VR for cable SPD - VR length of $10 \mathrm{~m}$ and EUT load power of $22 \mathrm{VAr}$

After thermal destruction of VR, voltage across EUT (Fig. 12) increases due to several reasons: residual voltage at EUT capacitor at the moment of VR's destruction, oscillation phenomena due to increased distance between SPD and EUT [15], as well as due to still large surge energy. Maximal value of voltage across EUT is now even larger than the insulation withstand impulse level of $1500 \mathrm{~V}$. This consequently means destruction of EUT.

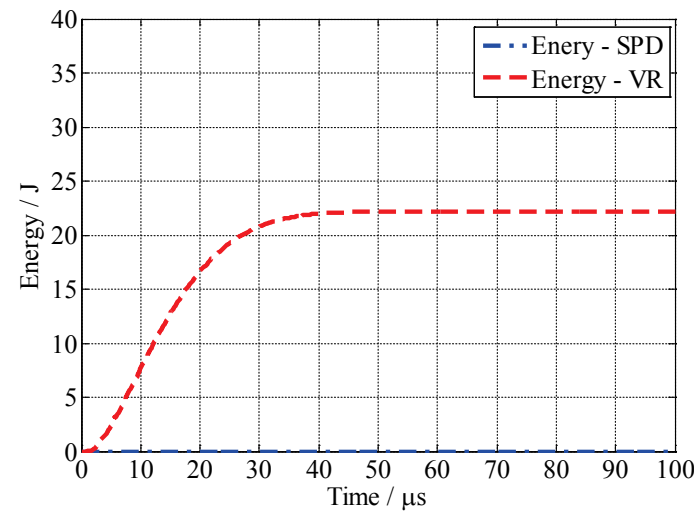

Figure13 Distribution of energy between SPD and VR for cable SPDVR length of $1 \mathrm{~m}$ and load power of $22 \mathrm{VAr}$
It is worthwhile to investigate whether EUT would survive after destruction of VR in case of very short cable SPD-VR. i.e. to investigate if there is protective effect of SPD located very close to EUT due to the fact that SPD's protection voltage is $1250 \mathrm{~V}$ and it is below the insulation withstand impulse level. For that purpose, energy distribution between SPD and VR for case of cable SPD$\mathrm{VR}$ length of $1 \mathrm{~m}$ and EUT load power of $22 \mathrm{VAr}$ is given in Fig. 13.

In this case of very short cable SPD-VR all surge energy is deposited in VR. Thermal destruction of VR will happen very fast, approximately at the time of $17 \mu \mathrm{s}$. After destruction of VR, voltage waveform across EUT is given in Fig. 14.

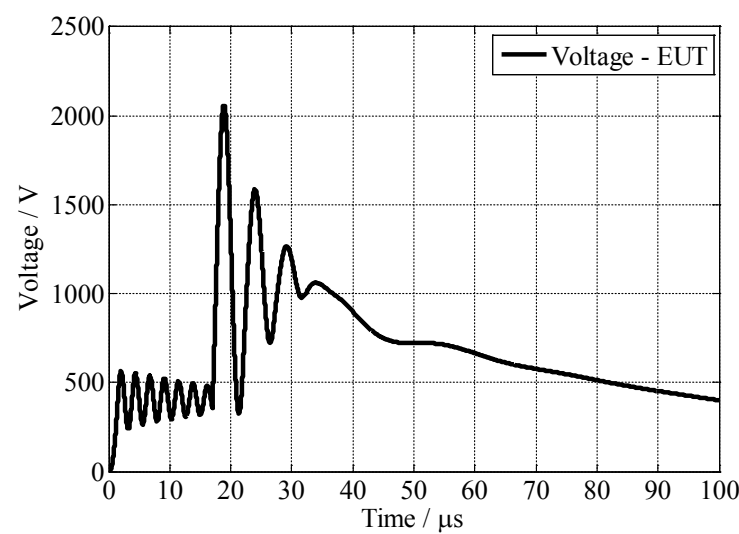

Figure 14 Voltage waveform across EUT after thermal destruction of VR for cable SPD - VR length of $1 \mathrm{~m}$ and EUT load power of $22 \mathrm{VAr}$

Maximal value of voltage across EUT is larger than insulation withstand level of EUT as well. Therefore, it can be concluded that values of maximal voltages across EUT given in Fig. 6 are valid only in cases when there is no thermal destruction of VR.

The previous analysis shows that for cable lengths between SPD at distribution board and EUT (more precisely VR in EUT) below certain value, there is no proper overvoltage protection, although two surge protective devices exist in the system. From Fig. 10 it can be seen that this critical value of distance between SPD and EUT is about $30 \mathrm{~m}$, which is very large value especially in case of residential buildings. Therefore, it can be concluded that every sensitive electric and/or electronic device equipped with varistors and switching mode power supply can be damaged if it is installed at distance less than $30 \mathrm{~m}$ from distribution board with SPD.

\section{Solution for proper overvoltage protection}

In order to provide reliable and proper overvoltage protection of electric and electronic devices it is necessary to assure survival of installed varistors.

The main precondition is that energy deposited in varistors is to be lower than its energy absorption capability. This should be fulfilled for all locations of the equipment within the installation regarding cable length between SPD installed at distribution board and connected equipment. There are two possible solutions:

- Solution I - to assure that most of the surge energy is deposited in SPD at distribution board. 
- $\quad$ Solution II - to install additional SPD(s) between SPD at distribution board and protected equipment which will share surge energy and decrease the value of energy deposited in varistor.

In order to assure that most of the energy is deposited in SPD located at the distribution board (Solution I), it is necessary to increase the voltage drop along the cable between SPD and VR. In that case, voltage across SPD will be high enough to bring SPD in state of large current conduction. This can be achieved by addition of decoupling element in series with cable SPD-VR. This decoupling element has to provide large value of voltage drop in case of surge appearance, and to provide small voltage drop and power losses in normal regime. For lowvoltage power systems it is better to use inductive than resistive decoupling element, because inductor generates large voltage drop for steep surge currents.

Solution II assumes application of SPDs in cascade arrangement starting at distribution board and downstream toward protected equipment. According to IEC standard 62305-1 [12], SPDs should be located at boundaries of Lightning Protection Zones (LPZ). For application discussed here, simple solution is to install SPD of Type 3 according to IEC standard 61643-11 [14] at power socket to which the equipment is connected. Simplified model of this solution is given in Fig. 15. It is taken that protection voltage of SPD Type 3 is $800 \mathrm{~V}$.

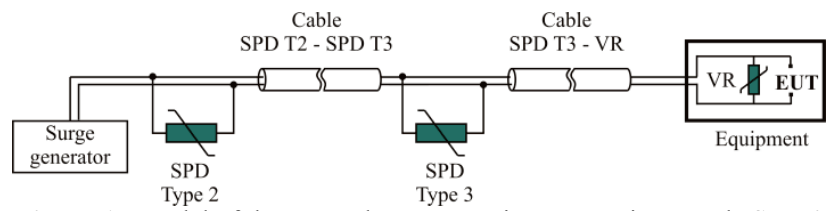

Figure 15 Model of the overvoltage protection system in cascade SPDs' arrangement

However, in this case an adverse issue of energy distribution between SPDs and VR arises again due to differences in their protection voltages and cable lengths between them. As example, distribution of energy between SPDs and varistor for case of length of cable between SPD Type 2 and SPD Type 3 of $10 \mathrm{~m}$, length of cable between SPD Type 3 and VR of $50 \mathrm{~cm}$ and capacitive load power of $22 \mathrm{VAr}$ is given in Fig. 16.

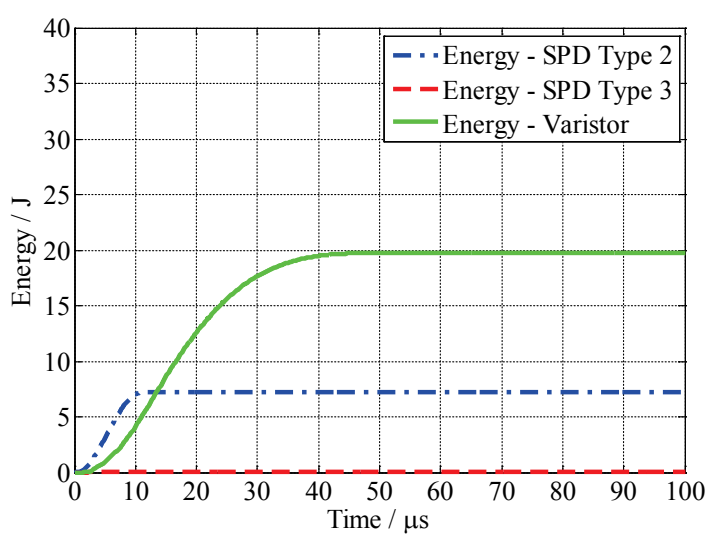

Figure 16 Distribution of energy between SPD Type 2, SPD Type 3 and VR for cable SPD T2 - SPD T3 length of $10 \mathrm{~m}$, cable SPD T3 - VR length of $0,5 \mathrm{~m}$ and EUT load power of $22 \mathrm{VAr}$
In this case, the most of surge energy is again deposited in varistor. Situation is similar to the case given in Fig. 11. The reason for this is lower protection voltage of VR than protection voltage of SPD Type 3 and very short cable length between SPD Type 3 and VR. Therefore, voltage drop across cable SPD Type $3-\mathrm{VR}$ is not enough to bring SPD Type 3 in state of current conduction and energy deposited in SPD Type 3 is equal to zero. As a conclusion, application of this SPD is unnecessary.

As in the Solution I, application of decoupling element(s) is necessary in Solution II as well. Decoupling element can be installed between SPD Type 2 and SPD Type 3 and/or between SPD Type 3 and VR.

Manufacturers of SPDs propose application of these decoupling elements for cases of cable lengths between SPDs stages shorter than $15 \mathrm{~m}$. However, obtained results show that application of decoupling elements is necessary for cases of cable lengths shorter than approximately 30 m (Fig. 10), especially for cases of equipment with installed varistors. These conclusions should be taken very seriously, because it practically means that for most of residential buildings application of decoupling elements is necessary regardless of cable lengths between surge protection devices and/or varistors within equipment. Additionally, most of electronic devices are portable and can be connected at different power sockets in installation.

As example, decoupling inductor with inductance of $12 \mu \mathrm{H}$ is applied for Solution I in model system in Fig. 1 . Distribution of deposited energy between SPD and VR for one of the most unfavourable cases with cable SPD -VR length of $1 \mathrm{~m}$ and EUT load power of $22 \mathrm{VAr}$ is given in Fig. 17.

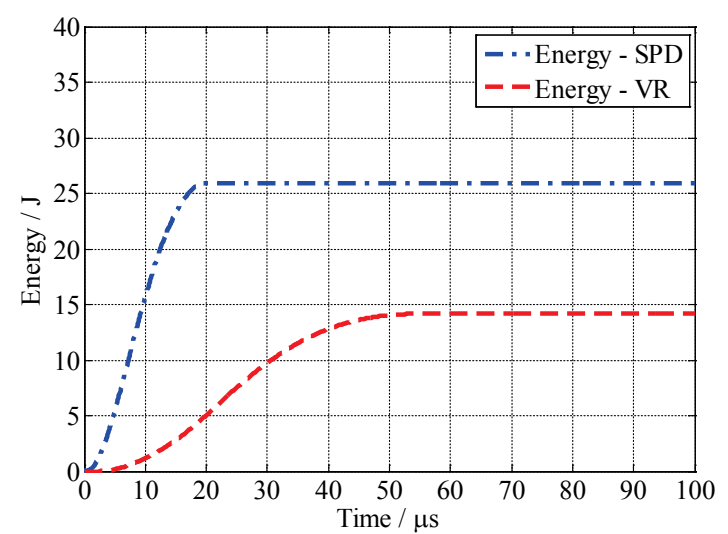

Figure 17 Distribution of energy between SPD and VR with application of decoupling inductance of $12 \mu \mathrm{H}$ in case of Solution I for cable SPD$\mathrm{VR}$ length of $1 \mathrm{~m}$ and load power of $22 \mathrm{VAr}$

It can be seen that energy deposited in SPD is higher than energy deposited in VR. Energy deposited in VR is very close to, but lower than its energy absorption capability.

Here is worthwhile to be mentioned that previously presented results and conclusions are obtained with application of Combination Wave surge. Additional analysis should be performed with other types of representative surges in order to provide overall analysis and confirmation. 


\section{Conclusion}

Wide application of sensitive electric and electronic equipment requires adequate and reliable overvoltage protection due to their low surge withstand capability. These devices are usually equipped with varistors which have very low protection voltages, which is often emphasised as their advantage by equipment's manufacturers. However, due to low energy absorption capability, these varistors may be thermally damaged when high voltage surges appear.

Application of surge protection devices (SPD) is required in order to provide efficient protection of equipment in low-voltage power installations against surges. The common situation, widely used especially in residential buildings, is application of only one SPD at service entrance or distribution board. Most of the users accept this situation due to confidence in building developers and in the device manufacturers.

In the paper, comprehensive analysis of this previously mentioned situation is given. The analysis has been conducted through experimental measurements and extensive number of simulations with wide ranges of influencing parameters. Obtained results show that even for relatively long cables between surge protection device (SPD) at distribution board and protected equipment (i.e. for equipment connection to the power installations at sockets relatively far from distribution board), proper protection characteristics cannot be obtained. Inadequate distribution of surge energies between SPD and built-in varistor leads to thermal destruction of the varistor. Furthermore, there is sudden increase of voltage across equipment elements which were to be protected by varistor. These voltages are higher than equipment withstanding impulse voltage, what causes failure of equipment. Similar situation is in the case of cascade application of SPDs installed at distribution board and downstream toward protected equipment.

A solution that provides proper performances of overvoltage protection (regarding varistor survival under high energy surges as well as regarding voltage values across protected equipment) is application of decoupling elements between SPD and equipment (i.e. varistor build in equipment). It should be kept in mind that practically for most of the residential buildings application of decoupling elements is necessary.

Further investigations should be performed with other types of representative surges in order to provide overall analysis and confirmation.

\section{References}

[1] He, J.; Yuan, Y.; Xu, J.; Chen, S.; Zou, J.; Zeng, R. Evaluation of the effective protection distance of lowvoltage SPD to equipment. // IEEE Trans. Power Del. 20, 1(2005), pp. 123-130. DOI: 10.1109/TPWRD.2004.835254

[2] Radulović, V.; Škuletić, S. Influence of Combination Wave Generator's current undershoot on overvoltage protective characteristics. // IEEE Trans. Power Del. 26, 1(2011), pp. 152-160. DOI: 10.1109/TPWRD.2010.2060501

[3] IEEE Guide on the Surge Environment in Low-Voltage $(1000 \mathrm{~V}$ and Less) AC Power Circuits, IEEE C62.41.12002 Standard, April 2003.
[4] Paul, D. Low-voltage power system surge overvoltage protection. // IEEE Trans. Ind. Appl. 37, 1(2001), pp. 223229. DOI: $10.1109 / 28.903152$

[5] Metwally, I. A.; Heidler, F. Enhancement of the SPD residual voltage at apparatus terminals in low-voltage power systems. // IEEE Trans. Power Del. 22, 4(2007), pp. 2207-2213. DOI: 10.1109/TPWRD.2007.905563

[6] Chen, L.; Jinliang, H.; Zhanqing, Y.; Zhiyong, Y.; Shunchao, W.; Jun, H.; Rong, Z.; Shuiming, C. Effective protection distances of SPDs for household electrical appliances. // IEEE Trans. Electromagn. Compat. 53, 3(2011), pp. 690-699. DOI: 10.1109/TEMC.2011.2112368

[7] Luo, X.; Du, Y.; Wang, X. Transient responses of switching mode power supplies under a lightning surge. // Proceedings of IEEE Industry Applications Society Annual Meeting (IAS) / Orlando, 2011

[8] Milardić, V.; Uglešić, I.; Pavić, I. Surge protection of buildings connected to an overhead low-voltage network. // Energija. 55, 3(2006), pp. 352-371.

[9] Mi, Z.; Jianguo, W.; Xuan, F.; Li, C.; Chunhua, F.; Jian, X.Influence of Power-Line Coupling/Decoupling Network on Output Characteristics of the Combination Wave Generator. // IEEE Trans. Power Del. 26, 4(2011), pp. 2333-2341. DOI: 10.1109/TPWRD.2011.2167161

[10] Horváth, I. Simulation of a memristor-spark-gap model for lightning protection purposes. // Tehnicki vjesnik-Technical Gazette. 21, 5(2014), pp. 1047-1050.

[11] Kladar, D.; Martzloff, F. Facts, fiction, and fallacies in SPD design and applications. // Proceedings of Power Engineering Society General Meeting / Montreal, 2006. DOI: 10.1109/pes.2006.1709258

[12] Radulović, V.; Mujović, S.; Miljanić, Z. Characteristics of Overvoltage Protection with Cascade Application of Surge Protective Devices in Low-Voltage AC Power Circuits. // Advances in Electrical and Computer Engineering. 15, 3(2015), pp. 153-160. DOI: 10.4316/AECE.2015.03022

[13] Insulation coordination for equipment within low-voltage systems - Part 1: Principles, requirements and tests, IEC Std. 60664-1 Standard, 2002.

[14] Low-voltage surge protective devices - Part 11: Surge protective devices connected to low-voltage power systems - Requirements and test methods, IEC 61643-11 Standard, March 2011.

[15] Protection against lightning - Part 4: Electrical and electronic systems within structures, IEC Std. 62305-4 Standard, 2006.

[16] IEEE Recommended Practice on Characterization of Surges in Low-Voltage (1000 V and Less) AC Power Circuits, IEEE C62.41.2-2002 Standard, April 2003.

[17] Electromagnetic compatibility (EMC) - Part 4-5: Testing and measurement techniques - Surge immunity test, IEC Std. 61000-4-5 Standard, 2005.

[18] IEEE Recommended Practice on Surge Testing for Equipment Connected to Low-Voltage (1000 V and Less) AC Power Circuits, IEEE C62.45-2002 Standard, April 2003.

[19] Škuletić, S.; Radulović, V. Analysis of surge protection performance in low-voltage AC systems with capacitive load. // Proceedings of $45^{\text {th }}$ International Universities Power Engineering Conference / Cardiff, 2010.

[20] Mujović, S.; Đukanović, S.; Radulović, V.; Katić, V. Least Squares Modeling of Voltage Harmonic Distortion Due to PC Cluster Operation. // Advances in Electrical and Computer Engineering. 13, 4(2013), pp. 133-138. DOI: 10.4316/AECE.2013.04022

[21] Protection against lightning - Part 1: General principles, IEC 62305-1 Standard, 2006

[22] He, J.; Zhiyong, Y.; Shunchao, W.; Hu, J.; Chen, S.; Zeng, R. Effective protection distances of low-voltage SPD with 
different voltage protection levels. // IEEE Trans. Power Del. 25, 1(2010), pp. 187-195. DOl: 10.1109/TPWRD.2009.2035297

[23] Ziyu, H.; Du, Y. SPD Protection Distances to Household Appliances Connected in Parallel. // IEEE Trans. Electromagn. Compat. 56, 6(2014), pp. 1377-1385. DOl: 10.1109/TEMC.2014.2356400

\section{Authors' addresses}

Vladan Radulović, PhD, Assistant Professor

Faculty of Electrical Engineering, University of Montenegro Bulevar Džordža Vašingtona bb, 20000 Podgorica, Montenegro vladanra@ac.me

\section{Zoran Miljanić, PhD, Assistant Professor}

Faculty of Electrical Engineering, University of Montenegro Bulevar Džordža Vašingtona bb, 20000 Podgorica, Montenegro zormi@ac.me 